\title{
The catalytic effects of sulfur in ethane dehydroaromatization
}

Goodarzi, Farnoosh; Hansen, Lars P.; Helveg, Stig; Mielby, Jerrik Jørgen; Nguyen, Thoa T M; Joensen, Finn; Kegnæs, Søren

Published in:

Chemical Communications

Link to article, DOI:

$10.1039 / \mathrm{d} 0 \mathrm{cc} 00408 \mathrm{a}$

Publication date:

2020

Document Version

Peer reviewed version

Link back to DTU Orbit

Citation (APA):

Goodarzi, F., Hansen, L. P., Helveg, S., Mielby, J. J., Nguyen, T. T. M., Joensen, F., \& Kegnæs, S. (2020). The catalytic effects of sulfur in ethane dehydroaromatization. Chemical Communications, 56, 5378-5381. https://doi.org/10.1039/d0cc00408a

\section{General rights}

Copyright and moral rights for the publications made accessible in the public portal are retained by the authors and/or other copyright owners and it is a condition of accessing publications that users recognise and abide by the legal requirements associated with these rights.

- Users may download and print one copy of any publication from the public portal for the purpose of private study or research.

- You may not further distribute the material or use it for any profit-making activity or commercial gain

- You may freely distribute the URL identifying the publication in the public portal

If you believe that this document breaches copyright please contact us providing details, and we will remove access to the work immediately and investigate your claim 


\section{COMMUNICATION}

\section{The catalytic effects of sulfur in ethane dehydroaromatization}

Received 00th January 20xx Farnoosh Goodarzi, ${ }^{\mathrm{a}}$ Lars P. Hansen, ${ }^{\mathrm{b}}$ Stig Helveg, ${ }^{\mathrm{b}}$ Jerrik Mielby, ${ }^{\mathrm{a}}$ Thoa T.M. Nguyen, ${ }^{\mathrm{b}}$ Finn Joensen ${ }^{b}$ and Søren Kegnæs*a

Accepted 00th January 20xx

DOI: $10.1039 / x 0 \times x 00000 x$

In this work, we investigated the catalytic effect of adding sulfur on Zn/ZSM-5 catalyst for direct conversion of ethane to aromatics. We show that the continuous addition of hydrogen sulfide $\left(\mathrm{H}_{2} \mathrm{~S}\right)$ effectively stabalizes zinc, prevents coking and results in a highly selective and stable catalyst. Considering the high content of sulfur in shale gas resources, these results highlight the importance of investigating catalysts under realistic operating conditions.

The population growth and general progress in living standards have resulted in a gap between the production and demand of chemicals. As a consequence of the gradual depletion of oil reserves and the so-called 'shale gas revolution', the direct conversion of light alkanes such as methane and ethane into value-added chemicals has therefore attracted increasing interest. Ethane is the second most abundant compound in shale gas and the over-supply of ethane has decreased the prices over the last few years. ${ }^{1}$ In particular, ethane may be converted into valuable aromatic products such as benzene, toluene and xylene (BTX products), which are important intermediates in the production of several bulk chemical products.

The reaction pathway for the conversion of light alkanes to aromatics on pure acid HZSM-5 zeolite, proposed by Guisnet et al. $(1992)^{2}$, shows that the first step is dehydrogenation and demonstrated that the limiting step is the formation of alkenes from alkanes. Afterward, aromatics are formed through oligomerization of the alkenes, followed by, cyclization and hydrogen transfer. However, on pure ZSM-5, cracking is a competing reaction; therefore, a bi-functional catalyst helps to improve the direct conversion of alkanes to aromatics by first dehydrogenating the alkane with minimized cracking, subsequently oligomerizing and, eventually, aromatizing the

\footnotetext{
a. DTU Chemistry, Technical University of Denmark, Kemitorvet 207, DK-2800 Kgs. Lyngby, Denmark.E-mail: skk@kemi.dtu.dk.

b. Haldor Topsoe A/S, Haldor Topsøes Allé 1, DK-2800 Kgs. Lyngby, Denmark.

+ Electronic Supplementary Information (ESI) available: [details of any supplementary information available should be included here]. See DOI: $10.1039 / x 0 x x 00000 x$
}

alkenes. The most studied catalyst, which has shown high catalytic performance in this process, is zinc-containing ZSM-5, providing both dehydrogenating and acidic sites. ${ }^{3-7}$ However, the two most important challenges for this catalyst deactivation are coke deposition and zinc leaching under the reducing conditions of the process. Based on previous studies, ${ }^{8,9}$ the dissociation energy of $\mathrm{C}-\mathrm{C}$ bonds is lower than that of $\mathrm{C}-\mathrm{H}$ bonds; therefore, cracking reactions and rapid coke formation occur as a result. Consequently, an efficient active site is required to selectively activate the $\mathrm{C}-\mathrm{H}$ bond and suppress undesired $\mathrm{C}-\mathrm{C}$ bond cleavage.

In an industrial perspective sulfur compounds are generally considered a poison to most heterogeneous catalysts. ${ }^{10}$ However, in some processes sulfur has been proven to enhance the activity or modify the selectivity such as Fischer-Tropsch synthesis, ${ }^{11,12}$ catalytic reforming, ${ }^{13,14}$ and hydrogenation of hydrocarbons ${ }^{15-17}$ as well as hydrocarbon oxidation ${ }^{18,19}$. Nowadays, different sulfide catalysts are widely used in hydrogenation processes. ${ }^{20,21}$ Natural gas typically contains sulfur, ranging from ppmv to percent levels. Therefore, in catalytic processing of natural gas liquids ( $\mathrm{C}_{2}+$ hydrocarbons), sulfur tolerant catalysts would be preferred, thus saving the cost associated with the removal of sulfur contaminants such as hydrogen sulfide and mercaptans from the feed stream. In case of direct conversion of sulfur-containing light alkanes to aromatics, sulfur converts to $\mathrm{H}_{2} \mathrm{~S}$ that is easily separated (and recycled to the reactor) from the liquid aromatic product.

Metal sulfides are promising catalysts for catalytic dehydrogenation of alkanes by improving catalytic activity and suppressing coke formation ${ }^{22-26}$. Resasco et al.22 showed that nickel sulfide catalysts improved isobutene selectivity and decreased the rate of coke deposition; however, catalytic activity was not high in the dehydrogenation of isobutane. In addition, Wang et al.,23,25,27 investigated the performance of different metal sulfide catalysts and demonstrated that sulfided catalysts had higher catalytic performance in the first $30 \mathrm{~min}$ of the reaction compared to metal oxide catalysts. Given this study on metal sulfides, sulfided zinc-containing ZSM-5 may be the 
ideal stable catalyst for ethane dehydroaromatization by utilizing the sulfur compound in the feed stream to stabilize zinc and reduce coke formation.

Therefore, in our work, the performance of sulfided Zn/ZSM-5 catalyst was investigated in an $\mathrm{H}_{2} \mathrm{~S}$ containing ethane feed and compared to $\mathrm{Zn} / \mathrm{ZSM}-5$ operating under sulfur-free conditions at $550{ }^{\circ} \mathrm{C}$. The ZSM-5 zeolite used in this work was synthesized conventional HZSM-5 zeolite (synthesis procedure is in supporting information), designated as ZSM-5. The zeolite was impregnated with zinc nitrate to achieve $5 \mathrm{wt} \% \mathrm{Zn}$ in the catalyst, designated as ZSM-5-Zn. The ZSM-5-Zn catalyst was sulfided in the reactor under $\mathrm{H}_{2} \mathrm{~S} / \mathrm{N}_{2}$ flow (500 ppmv $\mathrm{H}_{2} \mathrm{~S}$ in $\mathrm{N}_{2}$ ) and assigned as ZSM-5-Zn-S.

X-ray powder diffraction patterns of ZSM-5-Zn and ZSM-5-Zn-S samples show the characteristic diffraction peaks of the MFI zeolite structure (Fig. S1). Nitrogen physisorption isotherms of ZSM-5 is also presented in Fig. S1. Type I isotherm was observed in $\mathrm{N}_{2}$ adsorption-desorption isotherm study of the zeolite sample, which confirms the microporous structure of the synthesized zeolite. Textural properties of the synthesized ZSM5 is summerized in Table S1. SEM-EDS elemental mapping of Zn and $\mathrm{S}$ for ZSM-5-Zn-S shows a uniform distribution of the zinc and sulfur in the sample (Fig. S2).

To determine the effect of sulfidation on zinc, XPS characterization was performed on ZSM-5-Zn and ZSM-5-Zn-S. Fig. 1 shows the deconvoluted spectra of $Z n 2 p_{3 / 2}$ for the two samples. The characteristic peak in ZSM-5-Zn sample at 1022.4 $\mathrm{eV}$ is assigned to the $\mathrm{Zn} 2 \mathrm{p}_{3 / 2}$ peak of $\mathrm{Zn}^{2+}$. The observed binding energy for the aforementioned peak is shifted $0.3 \mathrm{eV}$ towards higher energy in the case of ZSM-5-Zn-S. In a previous study done by Ali et al., ${ }^{28}$ it was demonstrated that this shift is caused because of $\mathrm{ZnS}$ species. Furthermore, deconvolution of $Z n 2 p_{3 / 2}$ peak for ZSM-5-Zn-S shows the presence of two zinc species. The peaks at lower and higher binding energy are attributed to $\mathrm{Zn}-\mathrm{S}$ and $\mathrm{Zn}-\mathrm{O}$ bond, respectively ${ }^{29}$. Therefore, the XPS result is evidence to the formation of zinc sulfide species.

Sulfidation of ZSM-5-Zn sample was studied using transmission electron microscopy (TEM). Fig. 2 shows TEM images of the asprepared ZSM-5-Zn and after 2 hours of exposure to $0.7 \mathrm{mbar}$ $\mathrm{H}_{2} \mathrm{~S}$ (equivalent to $\sim 700 \mathrm{ppmv} \mathrm{H}_{2} \mathrm{~S}$ under standard 1atm experiments) at $350 \stackrel{\circ}{\circ}$ in the microscope dedicated to sulfidation experiments ${ }^{30}$ (Supplementary Fig. S3). The TEM

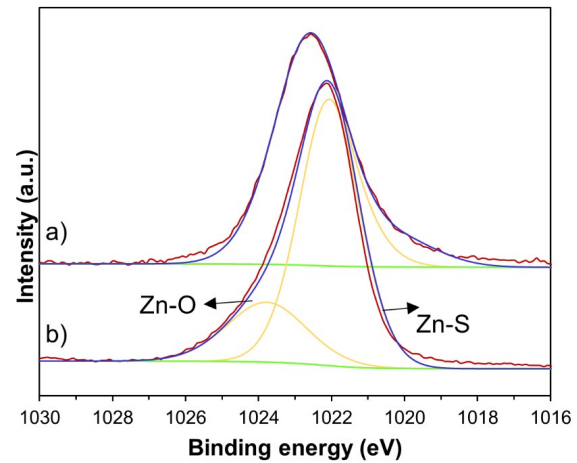

Fig. 1. XPS deconvolution spectra of $Z n 2 p_{3 / 2}$ level for a) ZSM-5-Zn and b) ZSM-5-Zn-S.
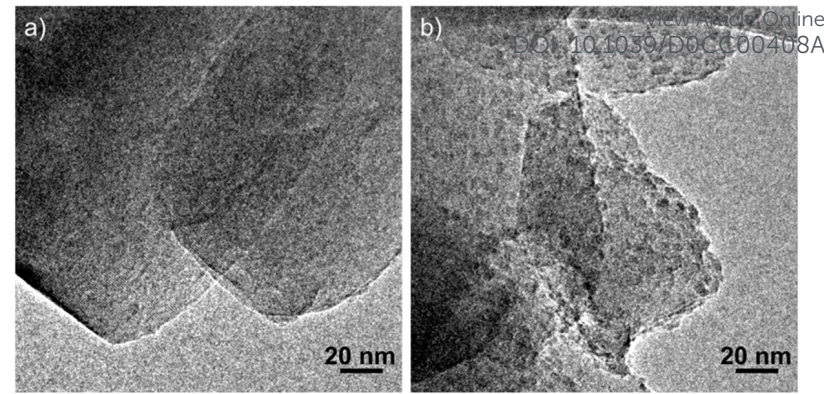

Fig. 2. TEM images of ZSM-5-Zn a) as prepared and b) after 2 hours sulfidation in dedicated electron microscope under exposure to $0.7 \mathrm{mbar}_{2} \mathrm{~S}$ at $350 \stackrel{\circ}{ } \circ$.

image in Fig. 2a reveals parts of two zeolite crystals of uniform contrast with the crystal to the left showing lattice fringes of spacing $0.95 \mathrm{~nm}$ in accordance with (111) planes of the ZSM-5 (MFI) structure. Fig. $2 \mathrm{~b}$ shows that, after sulfidation, the zeolite crystals are decorated by dark contrasted nanoparticles ranging from 1.5-12.0 nm in size with an average diameter of $3.8 \mathrm{~nm}$ (based on 775 particles from 9 image areas. In addition, particle size distribution is provided in Fig.S4). Considering the comparable sulfidation conditions between TEM and samples applied for XPS, these nanoparticles are likely zinc sulfide species since their presence was confirmed by XPS. We noted that the exposure to the electron beam prior to or during sulfidation more than a couple of minutes appeared to prevent or affect the formation of highly dispersed nanoparticles in 6 out of 6 measured image areas (Supplementary Information Fig. S5-S6). This effect was observed as absence of particles in previously imaged areas or disappearance of nanoparticles over time; however, the particle size distribution was not affected due to post-mortem imaging after sulfidation from areas not previously exposed to the electron beam. Therefore, Fig. 2 shows images from two different areas to represent stages and insights into the sulfidation process.

Table S2 summarizes the results obtained from ammonia TPD for measuring the concentration of acid sites in ZSM-5, ZSM-5$\mathrm{Zn}$ and ZSM-5-Zn-S. Results obtained from ammonia temperature-programmed desorption (TPD) at temperatures between 180-550 ㄷ $\mathrm{C}$ show that the introduction of zinc reduces the concentration of strong acid sites, which are attributed to Brønsted acid sites, from 0.09 to $0.04 \mathrm{mmol} / \mathrm{g}$. However, sulfidation has almost no effect on the total acidity of the treated ZSM-5-Zn sample.

The catalytic performance of ZSM-5-Zn was evaluated under sulfur-free conditions. Whereas ZSM-5-Zn-S catalyst was tested in ethane with $60 \mathrm{ppmv} \mathrm{H}_{2} \mathrm{~S}$ in the feed. The catalytic activity and BTX selectivity of the sulfided catalyst is compared to the relevant catalyst in the absence of sulfur, presented in Fig. 3, at $550{ }^{\circ} \mathrm{C}$ and 2 barg with gas hourly space velocity (GHSV) $=0.3 \mathrm{~h}^{-}$ 1. Fig. 4 a shows the conversion of ethane over ZSM-5-Zn without sulfur in the feed and ZSM-5-Zn-S in the presence of $60 \mathrm{ppmv}$ sulfur in ethane feed. The deactivation trends under sulfur-free conditions for ZSM-5-Zn and ZSM-5-Zn-S are very different. The 
initial conversion under sulfur-free conditions decreased rapidly from around $40 \%$ to almost $11 \%$ after $30 \mathrm{~h}$ of operation. On the contrary, the catalytic activity of ZSM-5-Zn-S in the presence of sulfur showed improved stability and slightly increased from $8 \%$ to $11 \%$ after $30 \mathrm{~h}$ on stream. Furthermore, the conversion over ZSM-5-Zn-S remains almost $11 \%$ after $40 \mathrm{~h}$ of time on stream while ZSM-5-Zn catalyst continues to deactivate (Fig. 3(a)). This may indicate that, in the presence of sulfur, this catalyst provides improved longevity. As Fig. $3 b$ shows, selectivity towards BTX has an increasing trend in the ZSM-5-Zn-S sample while it declines over time for the ZSM-5-Zn sample at a reaction temperature of $550 \circ \mathrm{C}$. BTX selectivity that decreased to around $12 \%$ under sulfur-free conditions for ZSM-5-Zn, showed an increasing trend over time for the sulfided Zn/ZSM-5 catalyst. In addition, already after 15 hours, the selectivity towards BTX for the ZSM-5-Zn-S catalyst exceeds that of the ZSM-5-Zn operating under sulfur-free conditions and reached $22 \%$ after $40 \mathrm{~h}$.

Coke analyses on the spent catalysts confirm that less carbon was deposited on the spent ZSM-5-Zn-S compared to spent ZSM-5-Zn (Table S3). Furthermore, residual zinc in the formerly spent catalyst is almost the same as in the fresh catalyst (only $10 \%$ loss) whereas, the latter had lost more than $50 \%$ of the zinc, indicating that the presence of sulfur effectively inhibits the leaching of zinc under operating conditions. The yield of other products such as $C_{1}$, ethylene and heavy aromatics $\left(C_{9+}\right)$ consisting of naphthalene derivatives over time are shown in
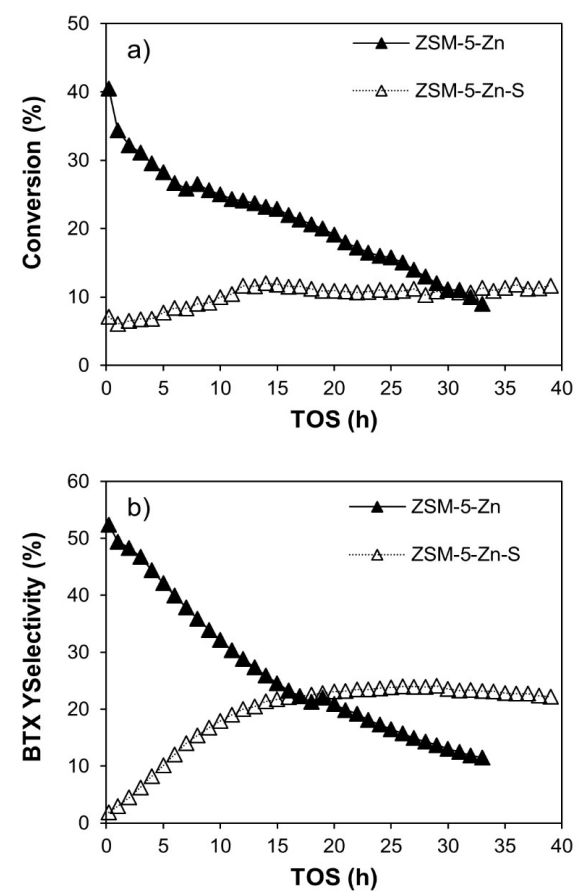

Fig. 3. a) Catalytic activity and b) BTX selectivity of ZSM-5-Zn in sulphur-free ethane feed and ZSM-5-Zn-S in the presence of 60 ppmv $\mathrm{H}_{2} \mathrm{~S}$ in ethane feed for ethane dehydroaromatization at $550^{\circ} \mathrm{C}, 2$ barg and GHSV $=0.3 \mathrm{~h}^{-1}$.
Fig. 4 for ZSM-5-Zn and ZSM-5-Zn-S catalysts vid $_{\text {Ar }}$ generalal, sulfidation of the catalyst has a profoundPlfluenę/बACC00408A product yields (see Fig.4 and Fig. S7): the sulfided catalyst produces virtually no methane (Fig. 4a) and much less heavy aromatics (Fig. 4c). Particularly interesting is the fact that, in the presence of $\mathrm{H}_{2} \mathrm{~S}$, ethylene selectivity decreases (Fig. S8) while BTX selectivity (Fig. 3) increases over time. To increase the conversion, ethylene must be converted by further reactions over strong acid sites to form aromatics to overcome the thermodynamic limitation in ethane dehydrogenation. Therefore, the lower conversion we observe on sulfided samples may indicate that insufficient acidity leads to the accumulation of ethylene but as time passes, the conversion
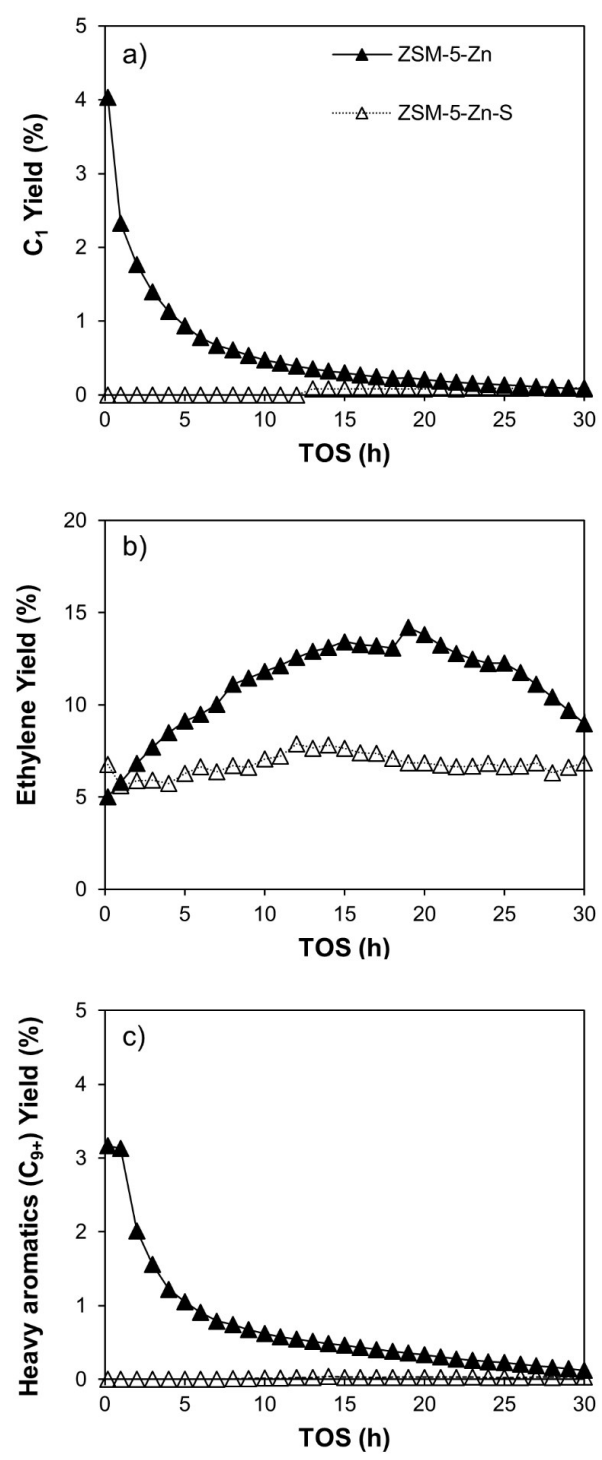

Fig. 4. a) $C_{1}$, b) ethylene and C) heavy aromatics yield for ZSM-5-Zn in sulphur-free ethane feed (filled triangles) and ZSM-5-Zn-S in the presence of 60 ppmv $\mathrm{H}_{2} \mathrm{~S}$ in ethane feed (empty triangles) for ethane dehydroaromatization at $550{ }^{\circ} \mathrm{C}, 2$ barg and GHSV $=0.3 \mathrm{~h}^{-1}$. 
increases and remains stable (Fig. 3). From our results, it looks like that rate of dehydrogenation and aromatization reaches a balance after some 10-15 hours. Since ethylene selectivity is dependent on aromatization rate, the decrease of ethylene selectivity for sulfided catalyst over time is due to increase of ethylene conversion to aromatics.

Based on our previous results ${ }^{31}$, we propose that $\mathrm{ZnOH}^{+}$species, which are weak acid sites ${ }^{32}$, is responsible for dehydrogenation of ethane to ethylene. Notably, the $\mathrm{NH}_{3}$-TPD of the sulfided and non-sulfided catalysts show a similar density of weak acid sites. Therefore, we speculate that the active $\mathrm{ZnOH}^{+}$are largly unaffected by the sulfidation. As previously emphasized, the strong acid sites catalyze the oligomerization and cyclization, which increases the conversion of ethylene. Despite the similar concentration of strong acid sites presented in Table S3, we did observe a 14 o $\mathrm{C}$ shift towards lower temperatures in the $\mathrm{NH}_{3-}$ TPD (Fig.S9). This indicates that the sulfidation decreases the strength of the strong acid sites, which may also explain less coke formation and selectivity towards heavy aromatics. The intimate mechanistic details remain unclear but will be the topic of future studies.

\section{Conclusions}

In conclusion, we investigated the influence of sulfur on the catalytic performance and selectivity of ZSM- 5 containing $5 \mathrm{wt} \%$ $\mathrm{Zn}$ catalyst in the direct conversion of ethane to BTX. Presence of zinc sulfide species was confirmed by XPS and the formation of these species was observed by TEM. Catalytic results showed that the presence of sulfur effectively reduces the selectivity towards undesired methane and heavy aromatics products. In addition, even though initial BTX selectivity decreases compared to the sulphur-free analogue, it has an increasing trend over time and seems to remain stable even after 40 hours on stream. On the contrary, the sulfur-free catalyst selectivity towards BTX shows a decreasing trend. Thus, we believe that with optimizing the amount of sulfur in the feed, zinc sulfide catalysts can be promising catalysts in dehydroaromatization of ethane.

\section{Conflicts of interest}

There are no conflicts to declare.

\section{Notes and references}

1 Y. Xiang, H. Wang, J. Cheng and J. Matsubu, Catal. Sci. Technol., 2018, 8, 1500-1516.

2 M. Guisnet, N. S. Gnep and F. Alario, Appl. Catal. A Gen., 1992, 89, 1-30.

3 Y. Ono, H. Nakatani, H. Kitagawa and E. Suzuki, in Studies in Surface Science and Catalysis, Elsevier, 1989, vol. 44, pp. 279-290.

4 F. Roessner, A. Hagen, U. Mroczek, H. G. Karge and K. H. Steinberg, in Studies in Surface Science and Catalysis, 1993, vol. 75, pp. 1707-1710.

View Article Online

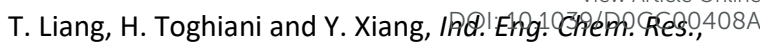
2018, 57, 15301-15309.

6 J. Zhang, W. Qian, C. Kong and F. Wei, ACS Catal., 2015, 5, 2982-2988.

7 F. Goodarzi, R. Pulikkal Thumbayil, K. Enemark-Rasmussen, J. Mielby, T. T. M. Nguyen, P. Beato, F. Joensen and S. Kegnaes, ChemCatChem, 2019, cctc.201902123. L. F. Halle, R. Houriet, M. M. Kappes, R. H. Staley and J. L. Beauchamp, J. Am. Chem. Soc., 1982, 104, 6293-6297. M. R. A. Blomberg, P. E. M. Siegbahn, U. Nagashima and J. Wennerberg, J. Am. Chem. Soc., 1991, 113, 424-433. J. K. Dunleavy, Platin. Met. Rev., 2006, 50, 110.

J. A. Kritzinger, Catal. Today, 2002, 71, 307-318.

R. ANDERSON, J. Catal., 1965, 4, 56-63.

P. Biloen, J. N. Helle, H. Verbeek, F. M. Dautzenberg and W. M. H. Sachtle, J. Catal., 1980, 63, 112-118.

C. Laiyuan, N. Yueqin, Z. Jingling, L. Liwu, L. Xihui and C. Sen, Appl. Catal. A Gen., 1993, 97, 133-143.

A. J. McCue, A. Guerrero-Ruiz, C. Ramirez-Barria, I. Rodríguez-Ramos and J. A. Anderson, J. Catal., 2017, 355, 40-52.

F. M. McKenna, R. P. K. Wells and J. A. Anderson, Chem. Commun., 2011, 47, 2351-2353.

F. M. McKenna, L. Mantarosie, R. P. K. Wells, C. Hardacre and J. A. Anderson, Catal. Sci. Technol., 2012, 2, 632.

G. Corro, R. Montiel and C. Vázquez L, Catal. Commun., 2002, 3, 533-539.

H. Yao, J. Catal., 1981, 67, 231-236.

S. E. Skrabalak and K. S. Suslick, ChemInform, , DOI:10.1002/chin.200542024.

N. A. Dhas, A. Ekhtiarzadeh and K. S. Suslick, J. Am. Chem. Soc., 2001, 123, 8310-8316.

D. Resasco, B. Marcus, C. Huang and V. Durante, J. Catal., 1994, 146, 40-55.

G. Wang, C. Li and H. Shan, ACS Catal., 2014, 4, 1139-1143. Y. P. Tian, Y. A. Liu, X. M. Liu and Z. F. Yan, Catal. Sci. Technol., 2018, 8, 5473-5481.

G. Wang, C. Gao, X. Zhu, Y. Sun, C. Li and H. Shan, ChemCatChem, 2014, 6, 2305-2314.

Y. nan Sun, L. Tao, T. You, C. Li and H. Shan, Chem. Eng. J., 2014, 244, 145-151.

G. Wang, Z. Meng, J. Liu, C. Li and H. Shan, ACS Catal., 2013, 3, 2992-3001.

A. Ali, G. Rahman, T. Ali, M. Nadeem, S. K. Hasanain and M. Sultan, Phys. E Low-Dimensional Syst. Nanostructures, 2018, 103, 329-337.

K. Ahn, J. H. Jeon, S. Y. Jeong, J. M. Kim, H. S. Ahn, J. P. Kim, E. D. Jeong and C. R. Cho, Curr. Appl. Phys., 2012, 12, 1465-1469.

30 S. Helveg, J. Catal., 2015, 328, 102-110.

31 F. Goodarzi, R. P. Thumbayil, K. Enemark-Rasmussen, J. Mielby, T. T. M. Nguyen, P. Beato, F. Joensen and S. Kegnæs, ChemCatChem, 2020, cctc.201902123. V. B. Kazansky, V. Y. Borovkov, A. I. Serykh, R. A. van Santen and B. G. Anderson, Catal. Letters, 2000, 66, 39-47. 

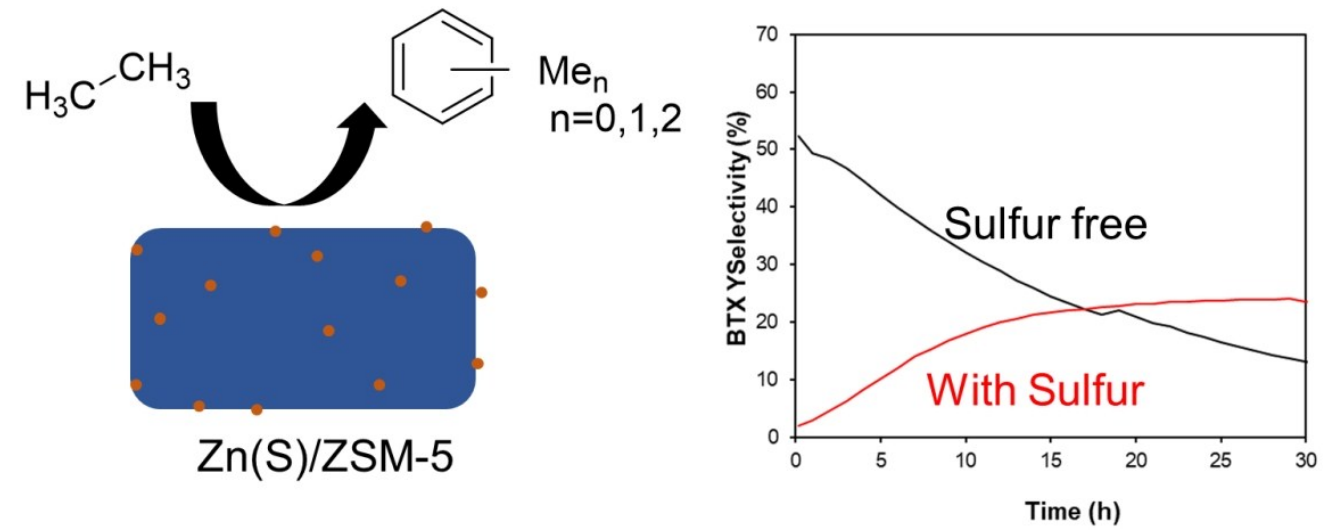